\title{
El mapuzungun en Puelmapu, entre 1885 y 1945. Territorios eruditos y territorios sociales
}

\author{
Marisa Malvestitti ${ }^{1}$ \\ Universidad Nacional de Río Negro, Argentina
}

\begin{abstract}
Resumen
Este artículo aborda, desde un enfoque historiográfico lingüístico, los estudios sobre el mapuzungun emprendidos en la actual República Argentina, en un eje temporal que abarca desde 1885 -finalización de la denominada "campaña del desierto"- a 1945. Se analiza la aparente escasez de trabajos relacionados con el tema, partiendo de referencias provistas por las bibliografías de síntesis sobre las lenguas indígenas del país que se produjeron en esos años, y mediante el análisis de distintos tipos de fuentes se describen los principales enfoques que adoptó la producción de la época en dos colectivos de investigación: actores integrados al Museo de La Plata e intelectuales territorianos del ámbito patagónico. Ello permite observar cómo se privilegió alternativamente el abordaje erudito documental basado en la valoración como referentes de los materiales jesuitas y trasandinos contemporáneos, y el análisis empírico de datos de campo.

Palabras clave: historiografía lingüística, tradiciones de investigación, mapuzungun, Museo de La Plata, intelectuales territorianos.
\end{abstract}

1 Para correspondencia, dirigirse a: Marisa Malvestitti (mmalvestitti@unrn.edu.ar), Mitre 630, 5to piso, San Carlos de Bariloche, CP 8400, Río Negro, Argentina. 
The Mapuzungun language in Puelmapu between 1885 AND 1945. SCHOLARLY TERRITORIES AND SOCIAL TERRITORIES

\begin{abstract}
This article deals with the studies on the mapuzungun undertaken in the Argentine Republic, in a period that spans from 1885 -the end of the so-called "desert campaign"- to 1945, from a Linguistic Historiography perspective. It analyses the apparent scarcity of works related to the subject among the references provided by the summary bibliographies on the country's indigenous languages produced during those years. Through the analysis of different types of sources, we describe the main approaches adopted by the linguistic and ethnological studies in those decades in two research groups: actors from the La Plata Museum and territorial intellectuals from the Patagonian area. This allows us to observe how was alternatively privileged the erudite documentary approach, based on evaluation Jesuit and contemporary trans-Andean materials as referents, and the empirical analysis of field data.
\end{abstract}

Keywords: Linguistic Historiography, research traditions, Mapuzungun, La Plata Museum, territorial intellectuals.

Recibido: 30/12/2019

Aceptado: 20/03/2020 


\section{INTRODUCCIÓN ${ }^{2}$}

En este artículo proponemos analizar algunas líneas de investigación desde las que se abordó el mapuzungun en la Argentina entre fines del siglo XIX y la primera mitad del XX. Según nuestra hipótesis, en la primera parte de este periodo el interés académico sobre el mapuzungun como objeto de análisis erudito se fragilizó, en tanto se expandía el de otras lenguas fuegopatagónicas, en particular el günün a iajüch y el aoneko 'a'ien en la Patagonia continental. Aun cuando se sostuvieron algunas investigaciones empíricas desde el Museo de La Plata y desde la agencia misionera salesiana, estas adolecieron de poca difusión de resultados. A la vez, fueron someros los procesos de revisión historiográfica sobre temas inherentes al idioma. Hacia inicios de la década de 1920, en cambio, se produjo una dinamización del campo debido a la emergencia de nuevos actores: los intelectuales territorianos que se encontraban en contacto directo con mapuchehablantes. Estos se vincularon con espacios académicos metropolitanos, pero su lugar en el campo científico fue más periférico que el de quienes se desempeñaban como investigadores en museos o profesores universitarios.

Adoptamos la perspectiva de la historiográfica lingüística (HL), según Koerner (1999) y Swiggers (2012). Este último autor señala como uno de los propósitos de la disciplina el exponer desde parámetros descriptivoexplicativos cómo se gestó el conocimiento lingüístico en determinado contexto. Tal estudio necesariamente incluye considerar el interjuego entre las continuidades y discontinuidades, tanto en la formación de conceptos, categorías y terminología, y en la determinación de los niveles de descripción

\footnotetext{
2 La investigación se enmarca en el proyecto PICT 2015-1507 “Tecnologías de papel. Patrones para la documentación y comunicación científica en los estudios de lenguas indígenas de Patagonia y Tierra del Fuego (1860-1930)", actualmente en curso y radicado en la Universidad Nacional de Río Negro. Una primera versión de este artículo se presentó en el Coloquio FONDECYT Regular 1170419 "Mediación lingüístico-cultural en los ámbitos de contacto mapudungun-castellano derivados del proceso de chilenización de la Araucanía: administración de justicia, producción etnográfica y lingüística y escolarización (18801930)", dirigido por Getrudis Payàs, que se realizó en la Universidad Católica de Temuco el 13 y 14 de agosto de 2018. La consulta al repositorio de la UMCE se efectuó en una estadía de investigación en el Departamento de Lingüística de la Universidad de Chile en agosto de 2017, que fue financiada por el FONDECYT 1150127 "Ideas lingüísticas en los debates sobre léxico y ortografía en Chile, 1875-1927" dirigido por Darío Rojas. Agradezco además a ambos colegas sus comentarios a versiones anteriores de este trabajo, así como la posibilidad de interactuar con integrantes de los equipos que trabajan sobre temáticas afines a las aquí desarrolladas.
} 
abordados, como en el establecimiento de relaciones interlingüísticas y atribución de funciones a una lengua determinada. De este modo, el historiógrafo lingüístico se convierte en un "observador", un "lector crítico" y también un "intérprete" de cómo ha evolucionado cierto saber lingüístico, a partir de una "actitud de empatía con el pasado" (Swiggers 2012: 42) y de la presunción de que las fuentes con las que trabaja aportarán entradas relevantes sobre el tema abordado. Además, retomamos algunos aportes de Koerner (1999) en cuanto a que la historiografía lingüística proporciona al lingüista material para adquirir un conocimiento del desarrollo de su propio campo, a modo de un conocimiento o "conciencia informada" (informed awareness) que le permite clarificar la procedencia de saberes, conceptos y técnicas que luego se establecieron como incuestionables.

En los estudios sobre lenguas indígenas, el periodo que analizamos estuvo dominado por el enfoque americanista; los datos lingüísticos constituían argumentos que colaboraban a reconstruir el pasado de la región. Tal como señala Pegoraro (2009: 16), quienes se dedicaron a estos temas en la Argentina produjeron una "americanización" del americanismo, "en diálogo con los círculos científicos más allá de las fronteras", pero con tintes locales en cuanto a las temáticas priorizadas. De este modo, en un contexto signado por la incorporación estatal de los territorios indígenas y la previsión de asimilación cultural de las comunidades, los estudios contribuyeron a consolidar en el plano ideológico ciertas afirmaciones que parecen continuar incontrastables aún en el presente. Entre ellas, que el pueblo mapuche proviene de Chile y por lo tanto constituye un elemento foráneo en el espacio pampeano-patagónico al este de los Andes, y que el mapuzungun, su lengua, se encuentra en un proceso de desplazamiento progresivo, aparentemente consentido por sus hablantes. Es por ello que reflexionar acerca de la constitución de saberes lingüístico en ese periodo, además de constituir un ejercicio analítico, puede contribuir a deconstruir algunas representaciones arraigadas, desde la perspectiva de ideologías lingüísticas expuesta, entre otros, por Irvine y Gal (2000) y Kroskrity (2004).

En síntesis, son objetivos del artículo analizar los enfoques mediante los que se abordó el análisis del mapuzungun en los estudios realizados en la Argentina en el periodo seleccionado, y de este modo, contribuir a develar las articulaciones, las tensiones y los efectos de las investigaciones realizadas sobre archivos previos y relecturas de obras publicadas, y exponer los acercamientos empíricos al campo que tendieron a la construcción de nuevos saberes contemporáneos. Para ello, indagamos en primer lugar cómo se consideró el mapuzungun en bibliografías lingüísticas nacionales y extranjeras de la época mencionada, y luego atendemos, en dos apartados sucesivos, a los aportes efectuados por dos agrupamientos de actores: los 
investigadores del Museo de La Plata y los intelectuales territorianos. Metodológicamente, recurrimos al análisis de distintas fuentes publicadas e inéditas, estas últimas relevadas en distintos repositorios del país, de Chile y de Alemania.

\section{INVESTIGACIONES SOBRE EL MAPUZUNGUN EN TERRITORIO ARGENTINO}

Según propone Da Rosa (2013) en su estudio historiográfico sobre lenguas indígenas rioplatenses, es en la década de 1880 cuando se produjo un cambio de perspectiva y comenzaron a aparecer trabajos que consideraban con mayor profundidad el tema indígena, y decantarían en un periodo posterior en aportes con perspectiva filológica. En la Argentina, a partir de 1885, cuando formalmente concluyó la denominada "campaña del desierto" conducida por Julio A. Roca, se detecta un fuerte interés en patrimonializar las lenguas originarias habladas en el país, aunque la ampliación de su estudio se realizó con distintos énfasis en las diversas regiones del país.

En el caso del mapuzungun, decreció el volumen de publicación, que en las décadas anteriores se observaba, de textos mediadores que propiciaban el acceso a entornos comunicativos en este idioma ${ }^{3}$. Pocos años antes, en 1871, desde el campo que hoy consideramos más propiamente lingüístico, Juan María Gutiérrez había publicado "Algunas observaciones sobre la lengua Araucana y Guarani" en la Revista del Río de la Plata. El trabajo partía de una pregunta clave en los trabajos filológicos de la época: el interrogante de si "la homogeneidad de estructura ó de formación" autorizaba "a asentar que todas las lenguas americanas son ramas del mismo tronco" (1871: 199). En el interrogante acerca de las relaciones interlingüísticas se inquiría también sobre ciertas cuestiones nodales para el americanismo: el origen

\footnotetext{
3 Entre ellas puede mencionarse la obra de Federico Barbará (1879) que se proponía como instrumento "para comprender y hacerse comprender de los indios" y así "ser útil a los indígenas y familias a cuyo cargo han sido puestos" (1879: 11), y los distintos instrumentos de evangelización redactados por los misioneros lazaristas (Savino 1876, entre otros). Esta línea de trabajo fue solo continuada posteriormente por la congregación salesiana, mediante los esfuerzos, principalmente, de Domenico Milanesio, quien incluso contribuyó a reeditar el Manual en 1900 para que fuera utilizado por los misioneros en la Patagonia, y produjo o adaptó otros textos con fines comunicativos para la tarea evangelizadora y con fines divulgativos de la congregación. (Nicoletti y Malvestitti 2008)
} 
del poblamiento americano y los agrupamientos etnológicos de las que la comunidad de idiomas podía dar cuenta ${ }^{4}$. Por otro lado, se observa que, aun cuando Gutiérrez partía de analizar la gramática del jesuita Andrés Febrés, también criticaba las producciones misioneras, tensión que se irá haciendo recurrente en otros escritos posteriores sobre la temática. En tal sentido, argumentó que estas complicaban "con los aparatos nebricenses el sencillo mecanismo de esta lengua verdaderamente primitiva cuya formación está sujeta a leyes que le son peculiares" (1871: 203). En su análisis del idioma destacó, entre otros aspectos, la homogeneidad del mapuzungun en la vastedad del territorio en que se utilizaba, su eufonía, su vocabulario "rico en denominaciones" (1871: 208) y su carácter de idioma "tan perfecto a la cultura general del pueblo que la habla" (1871: 200). Diez años después, Juan Larsen, a cargo de la reedición en Buenos Aires del Diccionario (1882) y la Gramática (1884) del jesuita Andrés Febrés, destacaba en el prólogo a esta última obra una ideología de utilidad del conocimiento del mapuzungun para los argentinos, en especial, para la correcta interpretación de topónimos y antropónimos, y para explicar "un sin número de voces de uso común" en el territorio nacional (1884: viii). Insinuó también que, incluso, si esa fuera la única lengua utilizada en Pampa y Patagonia podría estandarizarse un grafemario y constituir el vehículo de alfabetización para los indígenas, construyendo "sobre la doble base de la Gramática Araucana y del uso moderno de nuestros indios, el edificio para el cual estamos recién acumulando los materiales" (1884: viii). Su representación positiva también se apoyó en sus características sistemáticas: su carácter aglutinante, "su fonología tan libre de complicación" y "la asombrosa fecundidad de sus raíces" que permiten la polivalencia entre clases; destacó que "el araucano parece una lengua de conquistadores", concluyendo:

Bajo el punto de vista de la lingüística, y á parte de su uso práctico, el araucano merece que los filólogos se ocupen de él, pues su estudio promete resultados importantes para el progreso de la lingüística general, en que tanto brillan por su ausencia las lenguas Sud-americanas. (Larsen 1884: vi)

Se observa así que en los años previos a la campaña del desierto, el mapuzungun ofrecía una entrada a la eficacia comunicativa en espacios bilingües o plurilingües, a la vez que a los territorios eruditos del paradigma

4 En relación con algunos usos de la lingüística histórico-comparativa en contexto rioplatense en este mismo periodo, véase Ennis (2018). 
histórico-comparado. Pocos años después, la primera de estas concepciones se modificaría, ya que si bien se reconocía la presencia de poblador mapuche en los territorios y en la ciudad, comenzó a erosionarse la idea del pueblo mapuche como colectivo, en paralelo a la fragmentación y colonización de sus territorios. Así, por ejemplo, Adolfo Saldías, quien se ocupara de la edición de los papeles del exgobernador federal de Buenos Aires Juan Manuel de Rosas, afirmaba en el borrador de una carta escrita a Ernesto Renan, circa 1889:

Hoy casi ya no hay indios en la Pampa. El desierto ha ido desapareciendo bajo los ferro-carriles que costean las quebradas y cruzan los valles, transformados en fértiles campiñas. Donde antes se sucedían las tolderías se levantan hoy pueblos florecientes; y en las riberas y adyacencias de ríos caudalosos, se desenvuelven ya las industrias pastoriles y agrícolas por brazo del inmigrante europeo que tiene allí su porvenir asegurado $\mathrm{y}$ aun del indio mismo, convertido a la civilización por el trabajo y por la estabilidad del hogar de la familia que protege la ley y consagra la religión. El hijo del indio aprende el patrio idioma castellano en las escuelas Argentinas repartidas en aquella inmensa zona; y el estado y las asociaciones proporcionan a las mujeres indias los medios de educarse y de vivir de su trabajo en las Ciudades. (...) se puede afirmar que a principios del siglo que viene el pampa figurará entre las lenguas muertas y que de la raza pampa no quedarán sino vestigios". (Saldías, en Rosas 1947: 37)

De este modo, a partir de la diáspora producida por la deportación se comenzó a naturalizar como cliché que muchos mapuche se encontraban en las ciudades ya integrados a los sectores populares. Se describe que "más o menos civilizados, han vivido durante años diseminados entre los blancos. Los encontramos en el ejército y la armada, en la policía y los bomberos; el resto hace un poco de todo, lo que significa no mucho" (Ten Kate 1906: 52 , en francés en el original) ${ }^{5}$. Este proceso de subordinación sociopolítica tuvo efectos lingüísticos: se impuso el bilingüismo individual y social, se promovió el desplazamiento del idioma por el castellano, y comenzaron también a relevarse en los estudios estrategias de ocultamiento del idioma por parte de los hablantes. Por ejemplo, al relacionarse en La Plata a principios de la década del 20 con Juan José Catriel, "hijo mayor y legítimo del famoso

\footnotetext{
Todas las traducciones proporcionadas en el artículo nos pertenecen. Por otro lado, cabe destacar que afirmaciones prácticamente idénticas se encuentran en Lehmann-Nitsche (1906a y b).
} 
cacique Cipriano Catriel”, Roberto Lehmann-Nitsche recopiló un texto en mapuzungun, pero también "El cuento del 'Gran Tatr apai' -... dictado, directamente en castellano" (Lehmann-Nitsche 1930: 52). Poco después, en abril de 1925, el antropólogo realiza un viaje a las sierras de Cura Malal (Olavarría-Pigüé), al sur de la provincia de Buenos Aires, donde ubica a Matilde, prima de aquel, la que "no quería saber nada de sus paisanos... (ya que) esos tiempos se han acabado. No quería hablar en araucano sino en español"; de otro poblador, reporta, "no tiene mucho que contar, cuenta (números) en araucano". (Lehmann-Nitsche 1925)

En cuanto a la presencia del mapuzungun en los territorios eruditos de la época, más que en estudios gramaticales o filológicos, se evidencia en catálogos y estudios historiográficos acerca de las producciones realizadas con anterioridad sobre las lenguas amerindias. Los inventarios bibliográficos ofrecían un formato de entradas por lenguas, y títulos de publicaciones de referencia, en algunos casos ampliados con comentarios descriptivos o críticos sobre los materiales existentes (Niederehe 1995). Tomando como referentes los clásicos modelos de Hervás y Panduro (1800) y Adelung y Vater (1806-1817), las nóminas ofrecidas en este tipo de publicaciones en el sur de América contribuyeron a establecer una suerte de estado del arte, que como veremos en el caso del mapuzungun, se basó en referencias exiguas y recurrentes.

En uno de los primeros trabajos con explícitos propósitos historiográficos que se produjo en Chile, "La lingüística americana, su historia i su estado actual" (1893) de Diego Barros Arana y Rodolfo Lenz, partiendo de la preocupación americanistas antes mencionada, los autores proponían reflexionar sobre las similitudes (y divergencias) estructurales y fonéticas que presentaban las lenguas del continente americano, para concluir en la imposibilidad de postular "una unidad jeneral lingüística en América" (1893: 39). Respecto del "araucano", señalaron que aun cuando esta lengua se hablaba en un amplia y rica porción del territorio chileno, eran muy pocas las investigaciones contemporáneas: "fuera de dos reimpresiones (una abreviada) de la gramática de Febres, i otra de su vocabulario, no se ha hecho en este país durante el presente siglo más que un solo estudio sobre la lengua de esos indios" (1893: 47), en referencia a la obra de Luis Darapsky (1888) también basada en fuentes jesuitas. De modo similar, la Bibliografía de la Lengua araucana (1897) de José Toribio Medina recoge numerosas publicaciones históricas conocidas, tanto jesuitas como previas a las campañas, y para su actualidad, reporta las recientes publicaciones de Lenz y de Darapsky, así como de La Lengua araucana: notas bibliográficas, breve opúsculo dado a conocer en 1889 por Aníbal Echeverria i Reyes en Santiago. 
El itinerario bibliográfico sobre el "araucano" en la Argentina en el Catálogo razonado de la sección Lenguas americanas, de Bartolomé Mitre (1909), contiene una lógica similar. Según explica De Mauro (2018) el Catalogo de Mitre comenzó como un pasatiempo para su autor; luego esta actividad de síntesis descriptiva de su biblioteca se convirtió en una tarea a la que consagró buena parte de su tiempo. Esta autora señala que en diversas publicaciones Mitre comunicaba avances de su "catálogo metódico", que consta de "257 entradas para las lenguas indígenas de América del Sur (de las cuales más de 150 son lenguas habladas en el actual territorio argentino" (De Mauro 2018: 73). La actividad coleccionista de Mitre y la red de corresponsales que estableció le permitieron contar con un repositorio nodal en el país tanto respecto de publicaciones clásicas como recientemente registradas o editadas (Farro y De Mauro 2019). Por ello, aun cuando Luis María Torres advierte en el prólogo a la obra el recaudo de no considerar las fichas presentadas en el libro como "una bibliografía completa" (1909, I: xxiii), el carácter abarcador de la biblioteca lingüística americana reunida por Mitre - y publicada póstumamente- conduce a entender su selección como un inventario de los materiales fundamentales del campo. Así, Mitre reseña 26 obras acerca del mapuzungun (Título IV. De las lenguas americanas en particular, III. Araucano, T. I: 311-338). De ellas, quince corresponden a producciones misioneras de entre los siglos XVII a XIX (entre ellas, Luis de Valdivia, Bernardo de Havestadt, Andrés Febrés, Serviliano de Orbanel, así como la obra clásica de Thomas Falkner y el Pequeño Manual del Misionero de Pablo Savino (esta última cuenta con una ficha bibliográfica, pero no está comentada); seis, a obras de Rodolfo Lenz, y las cinco restantes comprenden textos basados en fuentes previas y publicadas fuera de la Argentina, como por ejemplo, Raoul de la Grasserie sobre la lengua auca, que juzga una "mera compilación... con algunas consideraciones superficiales sobre la lengua" (I: 319), un texto toponímico de Victor Chiappa, el colaborador de Lenz, o el volumen previamente mencionado de Darapsky. Es decir, entre los originados al este de los Andes, entonces, además de la obra de Savino y la traducción de de Angelis del volumen de Falkner -denostada por Mitre- solo se menciona el opúsculo de Juan María Gutiérrez ya descripto, que es evaluado como un "estudio didáctico literario... con las mismas tendencias filosóficas [que los textos que lo precedieron], pero con alguna más profundidad científica" (Mitre 1909, I: 319). En cambio, en las fichas no se consideran otros estudios recientes, como por ejemplo los de Lehmann-Nitsche sobre la narrativa mapuche que ya habían sido publicados (ver nota 5) o Milanesio (1898), donde incluso se había replicado una somera gramática del idioma.

Veinticinco años después, aparece en el primer tomo de la Historia de la Nación Argentina, dirigida por Ricardo Levene, el artículo "Lenguas 
indígenas del territorio argentino" (1936), debido al antropólogo italiano José Imbelloni, radicado en el país desde 1921. Allí este autor propuso una historización en la que destacó la etapa de fin de siglo XIX como crucial para el campo, señaló actores nacionales destacados y vinculó sus producciones con las que se desarrollaron contemporáneamente en los Estados Unidos de Norteamérica:

Hay que acercarse a la última década del 800 para encontrar un movimiento real y amplio de renovación en la ciencia lingüística americana. Casi contemporáneamente en América del Norte y en la del Sur surgen corrientes poderosas, con cuyo estímulo un grupo de americanistas ilustres reavivan el interés de los investigadores en torno al problema de las lenguas, y construyen, mediante la revisión crítica del inmenso acervo acumulado en los siglos precedentes, aquellas enciclopedias glotológicas que llevan los nombres de Brinton, Lafone Quevedo y Mitre. [...] entre nosotros la obra de Lafone y Mitre tuvo como continuadores únicamente a R. Lehmann-Nitsche y F. F. Outes. (Imbelloni 1936: 178)

De acuerdo con su perspectiva, el estudio académico de las lenguas originarias en el periodo que trató en su estudio se halló básicamente a cargo de bibliófilos y antropólogos. Por ello, citó entre las realizaciones metódicas y modernas en el país como figuras señeras al ya mencionado Bartolomé Mitre, y a tres destacados docentes investigadores de las Universidades de La Plata y Buenos Aires: Samuel Lafone Quevedo, Roberto Lehmann-Nitsche y Félix Outes. Imbelloni expuso en cuadros y mapas una sistematización acerca de las lenguas preexistentes de la Argentina, y consideró el criterio lingüístico en forma articulada con otros factores antropofísicos y culturales. Sobre "el mapuche", denominación que considera más aceptable que "araucano" (1936: 190), proveyó una sucinta descripción, que se infiere basada en las fuentes que señala acerca de la temática: en primer lugar, las Artes de Luis de Valdivia (1606) y Andrés Febrés (1765), junto con la Bibliografía de la lengua araucana de José Toribio Medina, arriba mencionada. A continuación, "entre los especialistas modernos", destaca a Félix de Augusta y Rodolfo Lenz, cuyas producciones ya databan de dos o tres décadas atrás. Finalmente, como publicación reciente Imbelloni mencionó el "Vocabulario Rankelche" elicitado por el checo Vojtech Frich en 1909 en el Territorio Nacional de La Pampa y publicado por Čestmir Loukotka en 1929. Esta síntesis permite observar que el autor no recogió publicaciones novedosas sobre el mapuzungun realizadas por investigadores del país o al este de los Andes, lo que implicaba o bien su inexistencia, o bien su irrelevancia. 
Las reseñas internacionales con propósitos afines de catalogación presentaban panoramas similares. Brinton (1891) solo menciona a Darapsky. La Grasserie (1891) se basa en Valdivia, Febrés, "un pequeño vocabulario y una pequeña gramática Auca, según Falcone, que encontramos en los manuscritos de la Biblioteca Nacional de París, sin indicación de fecha" y entre las obras modernas, los Estudios Araucanos de Lenz y L'esquisse de la langue des Moluches de Frédéric Müller (1891: 8). Finalmente, el texto de 1913 de Alexander Chamberlain, cuyo objeto era delimitar agrupamientos o stocks de lenguas amerindias, esquematizó un nítido recorte de tres agrupamientos lingüísticos en el área continental: Araucano (5), Puelche (63) y Tsoneca (75), y nuevamente fueron exiguas las fuentes citadas en el caso del "araucano": Mitre, Lenz y un vocabulario del siglo XVII publicado por Rodolfo Schuller en 1907 en Santiago. También Rivet (1924: 641) en su referencia a la "Famille Araukan" expuso brevemente su ubicación geográfica y los dialectos reconocidos hasta el momento, a partir de solo tres fuentes: Cañas Pinochet (1911), el diccionario de Augusta (1916) y el estudio de Lehmann-Nitsche sobre el grupo lingüístico Het (1922).

Por último, consideraremos los aportes de dos obras de divulgación editadas en la Argentina. En una obra con foco en la etnología, Los aborígenes de la República Argentina (1910), Félix Outes y Carlos Bruch afirmaron que hasta ese momento "no existe un estudio especial sobre los Araucanos argentinos" (1910: 113). Por ello, como base documental para el capítulo acerca de los pueblos indígenas de las llanuras, entre los que ubicaron a "los araucanos", recurrieron a antiguas crónicas y a una heterogénea selección de monografías de corte arqueológico y etnológico. No ofrecieron referencias específicas para el apartado "Caracteres lingüísticos", donde se aprecia la lengua como "idioma sonoro, distinto de los otros hablados por los indígenas argentinos", no gutural y eufónico, y con un rico vocabulario (1910: 107-108). A fin de profundizar en el tema, recomendaban la lectura de Una excursión a los indios ranqueles de Lucio V. Mansilla y dos novelas de Estanislao Zeballos, porque "reconstruyen, con vivo colorido y verdad, la vida indígena" y las luchas interétnicas desarrolladas en las épocas criolla y republicana (1910: 114). Por otro lado, en 1936 también se publicó Estado actual del estudio de las lenguas indígenas de Antonio Portnoy, que fue premiado por la Institución Mitre. En el abordaje de la "lengua araucana" (141-149), además de recurrir a los autores clásicos del campo (Valdivia, Falkner, Mitre, Darapsky, Lenz y Augusta), propuso considerar dos novedades en este tipo de trabajos. Por un lado, rescató los nombres de cuatro argentinos, que "lograron aprender el araucano merced a su contacto con los indios y colaboraron en la formación de un diccionario" (136: 145), según sus dichos, recopilado principalmente por Ventura Lynch (entendemos 
que con Federico Barbará). Por otro lado, destacó “el bien documentado estudio de Pablo Groeber" sobre toponimia araucana en el país, aparecido diez años antes (1936: 145).

Como puede verse, las nóminas precedentes construyeron para el mapuzungun una tradición básicamente dependiente de los estudios jesuitas y producidos fuera de la Argentina; y mencionaron esporádicamente algunos trabajos realizados en el país, generalmente de base empírica y producidos por misioneros o aficionados. De este modo consolidaron una historización de tipo erudito y en parte impulsada a la "caza de antepasados" (Koerner 1999: 382, en referencia a Raffaele Simone 1995). Además, salvo Imbelloni (1936), no discutieron los métodos y conceptos fundacionales del campo. Fue especialmente notoria la ausencia de estudios académicos en profundidad sobre el idioma desarrollados por filólogos formados, y hasta donde hemos podido explorar, excepto un caso particular, no se encuentran intelectuales, docentes o escritores mapuche que hayan sustentado demandas o efectuado producciones en mapuzungun 6 , tal como se registra en Chile a principios del siglo pasado.

\section{EL MAPUZUNGUN EN EL CONTEXTO DE LAS LENGUAS DEL ÁREA PAMPEANA}

En lo que sigue, nos abocaremos a revisar aportes de dos de las agencias desde las que se elaboró la cuestión desde fines del siglo XIX: los científicos del Museo de La Plata y los intelectuales territorianos. El Museo de La Plata, creado en 1888 y dirigido en su primera etapa por Francisco Pascasio Moreno, fue la institución argentina que contuvo desde sus inicios una clara y sostenida política de estudios filológicos que no se observa en otras instituciones nacionales ${ }^{7}$. Lafone Quevedo, quien sucedió a Moreno en

\footnotetext{
6 Para más información sobre esta cuestión, véase el dossier "Archivos indígenas: uso, circulación y apropiaciones de la escritura en Araucanía, Pampa y Patagonia" Quinto Sol, 23(3), 2019. [en línea]. Disponible en https://cerac.unlpam.edu.ar/index.php/quintosol/issue/ view/313 [Consulta: 10/11/2019].

7 Si bien desde el Museo Etnológico de la Universidad de Buenos Aires, creado en 1904, se realizaron documentaciones y estudios, estos no tuvieron en su época fundacional una envergadura y un respaldo institucional similares a los del Museo de La Plata (Domínguez, Luisa, c.p.).
} 
la dirección en 1906 y permaneció en ese rol hasta 1920, fue también el encargado de la sección Lingüística, y responsable por tanto de las políticas institucionales en esa área (Farro 2013). Lafone se dedicó en un primer momento, desde una perspectiva arqueológica, a exhumar manuscritos que contenían gramáticas sobre lenguas del Chaco. Se abocó además a la identificación de vestigios de la lengua cacán en la toponimia catamarqueña, ya que entendía que tales indicios lingüísticos le permitían explorar relaciones de contacto interétnico en periodos en los que otra documentación era escasa. Además, paulatinamente se interesó en realizar "un estudio general de las lenguas americanas para en seguida enfrentar la tarea de clasificarlas en su relación unas con otras" (Lafone Quevedo 1892: s/p). A este fin propuso, y trató de validar en sus estudios, una hipótesis propia: la existencia de "dos gramáticas matrices" en América del Sur que podían distinguirse según la posición en que ubican los morfemas pronominales: o bien prefijadoras (como el guaraní y otras lenguas "atlánticas"), o bien sufijadoras (como el quechua y otras lenguas “del Pacífico"). (Lafone Quevedo 1892 y 1900)

Hacia mediados de la década de 1890, Lafone inició un programa sistemático de estudios en relación con las lenguas de la Patagonia. La apertura de su archivo en los últimos años ha permitido comenzar a indagar sobre este aspecto de su labor lingüística, mucho menos conocido que sus trabajos sobre lenguas del Chaco. Observamos así que, por un lado, sistematizó en vocabularios manuscritos ordenados alfabéticamente las fuentes éditas e inéditas conocidas en la época sobre el günün a iajüch y el tehuelche, y produjo algunos nuevos datos empíricos sobre estos mismos idiomas interactuando con indígenas procedentes de la Patagonia en el Museo de La Plata (Farro, Máximo, c.p.; Malvestitti y Orden 2019). Por otro lado, contribuyó a develar cuáles eran las etnias que poblaban el área norte bonaerense en los siglos XVI y XVII, a partir de la revisión de copiosas fuentes históricas acerca de los "pampas". Esta inquietud temática será recurrente en la época, y constituyó, tal como señala Pegoraro "una de las maneras para los estudiosos locales de incorporarse a esta ciencia internacional americanista era instalando un tema sobre el cual los europeos no habían prestado atención: el Río de La Plata”. (Pegoraro 2009: 54)

En La raza pampeana y la raza guaraní, Lafone postuló la necesidad de distinguir étnicamente los pampas del siglo XVI de los del XVIII, ya que eso había creado el malentendido de que en los siglos XVI y XVII los mapuche "merodeaban" las pampas y "llegaban a las puertas de Buenos Aires" (Lafone Quevedo 1900: 30). Propuso considerar "la raza del Medio Pampeana que no es ni Guaraní ni Araucana” (p. 41), complejizando así un panorama étnico hasta entonces binario. Su planteo se centró en comprender las características de esta "raza" y también especificar los idiomas que sus 
integrantes empleaban. En la práctica, su propuesta tuvo como efecto ubicar el ámbito de acción del pueblo mapuche "a una y otra banda de la cordillera" (p. 31), entendiendo "que (no) entraron á la Pampa, antes del siglo XVII o principios el XVIII" (p. 72), producto de una migración desarrollada hacia el este en la que "se enseñorearon" de ese espacio (p. 92). En base a ello sostuvo que "las razas Guaraní, Chaco-Guaycurú, Pampa-Patagona y PampaAraucana son intrusas en el Río de La Plata, y que tal vez lo sea también, del todo ó en parte, la raza Pampa-Litoral (Chanás, Timbúes, Mbeguáes, etc.)" (Lafone Quevedo 1900: 94). Esta formulación puede que sea una de las primeras versiones académicas de la teoría sobre la araucanización de las Pampas ${ }^{8}$. La explicación de Lafone se apoyó, además, en la obra de Falkner (1774), que en este periodo fue ponderado en su círculo de intelectuales como autoridad de referencia para la comprensión de las dinámicas lingüísticas y étnicas en área pampeana.

Si curiosas han sido las migraciones de los Guaraníes, otro tanto puede decirse de las de los Pampas, que desde hace 150 años parece que se han vuelto Araucanos, siendo que anteriormente eran otra cosa.

Las dudas al respecto tienen una explicación muy sencilla: recién en el siglo pasado empezaron los de Buenos Aires á extenderse hacia fuera, y ya en este tiempo las pestes y las guerras habían de tal manera debilitado á los naturales de la Pampa, que éstos se habían visto obligados á llamar á sus aliados los Moluches, gente de raza Araucana, que incluye á Pehuenches, Ranqueles, etc. Una vez que éstos conocieron a la Pampa y sus ventajas, como lo mismo la extinción de los primitivos moradores en ella, empezaron á ocupar el territorio que fuera de los Pampas en tiempo de la conquista, en que á la sazón hormigueaban cientos de miles de cabezas de ganado vacuno y caballar.

¿Quiénes eran los predecesores del Araucano en la Pampa? El Padre Falkner nos lo dice: eran los Taluhet y Diuihet, ramas del tronco Patagón, uno de los grandes grupos de la Raza Pampeana de d'Orbigny. (Lafone Quevedo 1900: 92)

Cabe destacar que la preocupación sobre el origen histórico del pueblo mapuche (alternativamente asignado a procedencias de norte a sur, de sur

8 Ortelli (1996) señala que la aplicación de esta expresión a distintos procesos y periodos para explicar la presencia de elementos culturales en la región a partir de hipótesis migracionistas y difusionistas, sobre todo desde la década de 1950 por parte de investigadores adscriptos a la Escuela Histórico Cultural, ha simplificado y oscurecido el complejo proceso ocurrido en la región desde el siglo XVII. 
a norte, de este a oeste o de oeste a este) y el alcance geográfico posterior tanto del pueblo como de su lengua al oriente de los Andes constituyó una constante en distintas publicaciones de la época. Obsérvese en las siguientes citas las similitudes con los argumentos presentados9:

No se sabe con certeza hasta qué punto los araucanos se expandieron en los distritos occidentales de los miembros occidentales de la República Argentina. Sin duda, [el idioma] es hablado hasta cierto punto en esa dirección. (Latham 1868: 133)

[Los araucanos] han penetrado, apenas tres siglos há, por los Andes que allá son transitables por mil sendas, á la pampa abierta, [...] despojado á los tehuelches nómadas de sus tierras y reprimido á los querandís de raza guaraní $[\ldots]$, y plagado de su idioma el habla familiar de la futura metrópoli argentina. (Darapsky 1888: 3-4)

La lengua auca, que tiene muchos dialectos, es hablada por la familia lingüística aucana, que se encuentra a ambos lados de los Andes, es decir, por un lado en Chile y por otro en el país pampeano, pero la mayor parte de la raza se asienta en el propio Chile, de ahí el nombre chileno o araucano que se le ha dado a menudo. No se sabe cuál fue el punto de partida de la migración étnica, si fue del Pacífico a la Pampa o en sentido contrario, pero es más probable que fuera de este a oeste; hay, se dice, vestigios de una raza que había habitado anteriormente en Chile, que los aucas habían ido rechazando gradualmente y que aún no habían eliminado en la época de la conquista española; a partir de ese momento, las migraciones en sentido contrario pueden haber tenido lugar bajo la presión de los conquistadores. Pero muchos de los que ahora viven al este de los Andes hablan un idioma de una familia diferente. (La Grasserie 1891: 5)

En tanto el análisis en profundidad de este idioma no constituía su foco de interés principal, Lafone solo abordó el mapuzungun de manera lateral en su búsqueda de fundamentos lingüísticos para explorar relaciones tipológicas entre las lenguas de la Patagonia y el Chaco. Expuso así, en el trabajo que estamos analizando, los equivalentes de los lexemas agua-cabeza-dar, los

\footnotetext{
9 Años más tarde, la historización de Imbelloni ubica la lengua mapuche, junto con el kichua, como "lenguas procedentes del área Andina" (p. 183), fuera del agrupamiento de "lenguas de la Pampa", y enfatiza su origen al oeste de la cordillera, entendiendo que abarca desde Copiapó hasta Chiloé y solo "en tiempos relativamente recientes ha dominado la vertiente oriental de los Andes desde la provincia de San Juan hasta el territorio del Neuquén y gran parte de La Pampa y la Patagonia". (Imbelloni 1936: 190)
} 
posesivos y los pronombres personales (p. 104), y definió el mapuzungun como una lengua "subfijadora" que por ende "corresponde a la sección del Pacífico" (p. 121) - aunque agregó correctamente como nota que "esta lengua parece prefijadora en la posesión"-, y la consideró una lengua "uniforme" ya que tiene "una sola serie de pronombres personales y de posesivación" (p. 101). Finalmente señala:

Es de las lenguas fuertes, muy extendidas, y que siempre se ha impuesto a las otras sus vecinas que no sean la española. Es rica y armoniosa y ha sido estudiada a fondo por antiguos y modernos. (Lafone Quevedo 1900: 121)

Los "antiguos", según las fuentes a las que recurre, eran las Artes y Vocabularios de Valdivia, Havestadt y Febrés, y los "modernos", los Estudios Araucanos de Lenz. Del lado oriental, en cambio, no indica ningún antecedente arqueológico lingüístico de relevancia. Por otra parte, cabe destacar la similitud de las ideologías lingüísticas con valoración positiva que expone respecto de las indicadas en el apartado anterior de este artículo.

En Etnología argentina (1909), Lafone replica la idea de que la mayoría del trabajo descriptivo sobre el mapuzungun se ha realizado en Ngulumapu, aunque destaca otra faceta: la documentación de textos orales que su colega Roberto Lehmann-Nitsche venía realizando en el Museo de La Plata: "De la parte araucana, ...poco se ha hecho, y menos en la República Argentina", salvo el "mucho material acopiado en folk-lore y demás relativo a estos últimos pobladores de la Pampa nuestra" (1909: 213). En tanto su recopilación es actualmente accesible (Malvestitti 2012; Canio Llanquinao y Pozo Menares 2013) no nos extenderemos sobre ella, salvo para recordar que en la época fue muy poco divulgada. Detallaremos, en cambio, la conceptualización desde la que el antropólogo alemán abordó el idioma, según las notas inéditas de una conferencia en alemán realizada en 1901 en Buenos Aires. Allí, Lehmann-Nitsche remarcó una doble perspectiva en el estudio de los idiomas: el qué, su contenido, que "le es más comprensible al común de la gente", y el cómo, la gramática, como "una matemática avanzada, pero por eso mismo, inaccesible para la mayoría, por incomprensible" (Lehmann-Nitsche 1901, f. 2, en alemán en el original). Por su formación de antropólogo, Lehmann-Nitsche se dedicó a documentar el "qué" del idioma, pero solo publicó entre 1902 y 1926 13 textos narrativos (11 epew o cuentos y 2 nütram o relatos históricos y etnográficos), en su mayoría en traducciones al alemán. Esto explica el poco conocimiento activo que hubo en el país acerca de la recopilación por él efectuada. En el caso del "cómo", es decir, los estudios gramaticales, los 
referentes que destacó fueron, nuevamente, Valdivia, Febrés, Havestadt y Lenz. En Lehmann-Nitsche 1906b cuestionaría, replicando otro lugar común de la época, que los especialistas en filología apenas se preocupan por las lenguas primitivas, lugar que en cambio ocupaban, aun con sus limitaciones de formación, los antropólogos.

Se observa así cómo desde el Museo de La Plata se fueron desarrollando tanto aproximaciones arqueológicas con un enfoque erudito, que partían de fuentes existentes para intentar develar el pasado de las relaciones interétnicas en base a registros idiomáticos, como otras de corte empírico que registraban algunos usos lingüísticos contemporáneos. Vinculado con el primer enfoque, se detecta en la época algunos intentos de exhumación de materiales sobre el mapuzungun oriental. Por un lado, como mencionamos más arriba, comenzaba a conocerse la existencia del manuscrito del diccionario pampa de Juan Manuel de Rosas. Saldías, su descubridor, la ensalzó en una carta en la que intentaba ofrecer la edición de la obra a científicos franceses, como "única en su género y es además la primera que ve la luz pública. En la República Argentina no se conoce hasta ahora más que pequeños vocabularios de la lengua Pampa. Ellos datan del tiempo de las Misiones Jesuíticas y son muy defectuosos, pues aparecen mezcladas voces ranquelinas, araucanas y tehuelches" (1947: 35). Pero luego de presentarla en el XVII Congreso Internacional de Americanistas desarrollado en 1910 en Buenos Aires, descubrió con decepción que la mayor parte del texto consistía en una copia de Febrés, por lo que el proyecto de edición fue abandonado ${ }^{10}$. Por otro lado, en 1914 Outes dio a conocer "Un texto y un vocabulario en dialecto Pehuenche de fines del siglo XVIII con introducción y notas", cuyo manuscrito fuera ubicado por este investigador en el Museo Británico. La publicación reproducía un listado léxico y algunas frases que fueran recopiladas por un integrante de la expedición Malaspina. En ambos trabajos se observa otra preocupación de la época: la concerniente a la diferencia dialectal del mapuzungun, la que se elaboró mediante la "investigación arqueológica" de fuentes previas (Domínguez 2018) y el relevamiento del habla de interlocutores pampeano-patagónicos por parte de los dos académicos del Museo antes mencionados. Lafone Quevedo expuso en un cuadro presentado en uno de sus manuscritos, un conjunto de categorías dialectales que replicaban las de araucanística jesuita, en especial las ofrecidas en el siglo XVIII por Febrés y Falkner:

10 La obra se publicará recién en 1947 durante el gobierno de Juan Domingo Perón. 


\section{Dialectos Araucanos}

$\underline{\text { Puelche }(\text { Puel }=\text { este, }}$ y $\underline{\text { che }}=$ gente o Gente del Este

Tehuel $=\underline{\text { Sud y } \underline{\text { che }}=\text { gente }},=$ gente del Sud

Picunche - gente del Norte

Moluche $=$ guerrero, de molun, según Falkner / Mallun (cargar) Febrés)

Leubu - che

Pehuén - che $=$ pehuén - pino y los pinales / Pehuen - mapu la cordillera o tierra de los Pehuenches (Febrés)

Guilliche $=$ gente del oeste $($ ghuyli $=$ sur $)$ Beliches

Ranqueles gente de los cardales (Arg.) - Según Febrés Rancul = carrizo

o caña, y Rancul-hue $=$ carrizal $/$ que, es partícula que indica pluralidad

(Lafone Quevedo 1898, f. 18)

Por su parte, Lehmann-Nitsche recuperó alguna de esas categorías, que empleaban sus consultantes (nguluche, pikumche, huilliche), y se detuvo en particular en la de waizüfche, término que refiere a quienes poblaban los bordes de la cordillera. Instrumentalizó un registro sistemático de 345 enunciados, en el que recogió numerosos ejemplos de estructuras de la lengua y vocabulario regional, que complementaba los Diálogos de otras variedades dialectales publicados por Lenz (1895-1897). Otros trabajos de índole similar fueron las anotaciones léxicas de Carlos Ameghino, que desde su rol de naturalista viajero en campañas a la Patagonia en las que colaboraba con el Museo, registró en 1900 un listado alfabético de 226 palabras ordenadas alfabéticamente desde la lengua fuente, sustantivos, adjetivos, verbos y adverbios (Malvestitti 2018), y el ya mencionado vocabulario de Frich anotado en General Acha con Mariano Rosas/ Ketrewitu, cuyos alrededor de 400 lexemas permitían dar "una idea de las particularidades lexicográficas y fonéticas del araucano hablado por los antiguos habitantes de la Pampa Central". (Loukotka 1929: 71)

En síntesis, si bien se produjeron nuevos aportes desde el plano empírico, en esta primera época fueron escasas, esporádicas o tardías las publicaciones sobre el mapuzungun documentado en Puelmapu. A esto se sumó que en su mayor parte se trató de registros textuales y vocabularios en lugar de análisis o estudios profundizados. Fue Lehmann-Nitsche quien tuvo más continuidad en la temática, aunque sus esfuerzos se dispersaron en diversos tópicos y direcciones disciplinares. A esto hay que agregar que probablemente la objetivación lingüística del mapuzungun se consideró menos necesaria que la

11 En ambos casos se recurrió a instrumentos estandarizados: Ameghino utilizó la plantilla empleada para otras lenguas patagónicas por Francisco P. Moreno y Frich la Tabelle zur Aufnahme südamerikanischer Sprachen emanada del Real Museo Etnográfico de Berlin. 
de otras lenguas preexistentes del área pampeano-fuegopatagónica, en tanto ya contaba con distintas descripciones autorizadas. De este modo, se provocó una aparente detención de la investigación acerca del tema en la Argentina, en tanto que los estudios chilenos en Chile continuaban desarrollándose.

\section{LOS ESTUDIOS TERRITORIANOS}

La situación presentada en el apartado anterior comenzó a modificarse cuando las preguntas de investigación fueron retomadas y resignificadas por actores residentes y funcionarios de presencia asidua en los Territorios Nacionales. Martínez propone la categoría de intelectuales de provincia indicando que "un intelectual de provincia está en su espacio en una posición homóloga a la de un intelectual de la capital, aunque subordinada si lo miramos respecto de aquel y de la relación de un espacio con otro" (2013: 172). Tomando en cuenta la noción de escala, observa las dificultades de profesionalización y asimetrías de consagración, con la consiguiente dificultad de ingreso al mercado editorial que, en contraposición, se plasma en ediciones de autor. Por otro lado, el "halo de intelectualidad que marca más un lugar social que una competencia" (2013:175) produce según su análisis, una identificación "mucho más indeleble que la del prestigio científico o artístico (que debe renovarse en el tiempo) y tiende a generar espacios de poder permanentes" en relación con la consagración y admisión al campo (2013: 176). En este artículo denominamos a estos agentes intelectuales territorianos, debido a que los actores que consideramos desarrollaron su actividad cuando aún esos espacios del interior del país formaban parte de los Territorios Nacionales. Retomamos algunas de las ideas expresadas en las publicaciones de algunos de ellos más destacados en la Patagonia: Félix San Martín (1919), Pablo Groeber (1926), Juan Benigar (1924, 1925, 1926, 1927, 1981) y Tomas Harrington $(1922,1925,1936,1942)$. Los tres primeros se abocaron al área del Neuquén, en tanto que Harrington se desempeñó como maestro ambulante en el Territorio Nacional de Chubut y posteriormente como funcionario en La Pampa. En cuanto a labor édita, Groeber y San Martín produjeron sendos volúmenes toponímicos que fueron publicados. En cambio, la obra de Benigar y de Harrington fue dada a conocer en su mayor parte como artículos en revistas, y sus legados manuscritos inéditos están en posesión familiar o al momento son solo parcialmente ubicables.

En sus trabajos, estos intelectuales se abocaron a resolver incógnitas que los interpelaban a escala local, como la elucidación de las toponimias y los 
antropónimos, para los que recurrieron a análisis lingüísticos. En el caso de Benigar, también abordó aspectos de la fonología y la gramática sincrónica del araucano sobre la base principal de datos empíricos recolectados. Se observa así que si bien también consideraron las fuentes previas, frente a la mera presentación de las propias elucubraciones o la discusión sobre interpretaciones bibliográficas, ganaron peso en sus obras los aportes de los consultantes.

En lo concerniente a Chubut y Río Negro, este estudio refleja mi conocimiento personal, adquirido en innumerables viajes de Norte a Sur y de Este a Oeste, y viceversa, en coche, en carro, a caballo, en automóvil y en ferrocarril, durante los cuales he oído infinidad de veces y usado yo mismo en la conversación las palabras de referencia. Respecto de Santa Cruz, Neuquén y Mendoza, me valgo de datos suministrados por personas que viven o vivieron allí y de constancias existentes en libros, diarios y revistas. (Harrington 1942: 26)

A tres hombres de la parcialidad de Millain Kurikal, Enrique y Francisco Millain Kurikal y a Paulino Gatica, debo una crecida cantidad de explicaciones de nombres de la región entre la latitud de Las Lajas y el centro del departamento de Las Minas hasta el gran camino por EpuLauken. El indígena Juan Antonio Barro, hombre bastante anciano, oriundo del sud de Mendoza, me dio explicaciones fidedignas referente a esta región y Francisco Aninür, oriundo de zona boscosa de la cordillera de Temuco y conocedor del Neuquen boscoso sudoccidental, me suministró numerosos datos respecto a esta región. Son estos los indígenas que demostraron interés en las consultas y dieron sus informes con toda sinceridad y vivacidad inteligente de espíritu. (Groeber 1926: 6)

En cuanto a las ideologías, si bien no escaparon a los prejuicios de su tiempo, expresaron una mayor empatía con el pueblo mapuche y un reconocimiento explícito de las difíciles circunstancias históricas que sus integrantes debieron atravesar durante y posteriormente al awkan. En tal sentido, y a través de la difusión de sus publicaciones, se ubicaron como una suerte de comunicadores a audiencias más amplias y de alcance nacional, de las experiencias sociales relatadas por las personas mapuche con las que interactuaban o convivían.

...a raíz de la campaña de Roca, casi todas las entidades araucanas fueron obligadas a abandonar sus pagos; gran parte de ellos se refugió en Chile, de donde volvió solo uno que otro individuo, para radicarse en regiones que no había visto antes y con cuyos habitantes, igualmente ignorantes de las tradiciones locales, no tenía relaciones de ninguna clase. (Groeber 1926: 5) 
...(escuchando) a los viejos araucanos relatar, trémulo el labio, la odisea de las tribus en el desbande definitivo, los horribles sufrimientos de la huida a pie por el desierto, dejando a la vera de las sendas sus mujeres y sus hijos muertos por la sed, el hambre, el frío y la fatiga. (San Martín 1919: 16)

Esto es la breve historia de la Colonia Catriel, cuyo primitivo destino pronto sólo el nombre recordará. Es una historia sencilla, sin episodios de fuerza dramática, pero de una trágica tan desconsoladora como silenciosa, porque es típica en el proceso de la desintegración y desaparición de una raza fuerte otrora que por sus cualidades excelentes no merece tan triste destino. Si ella va sucumbiendo, no es por su inadaptabilidad a las condiciones de vida creadas por la conquista de sus tierras, sino por la incuria de un conquistador que no se preocupó de crear para el vencido un lugar adecuado y digno dentro de la engrandecida patria argentina. [...] Pero temo que e1 historiador futuro tendrá que constatar: "El problema de los araucanos argentinos fue resuelto por su desaparición”. (Benigar 1926: 45, 48)

Los araucanos, que al fin comprenden, después de lucha secular, que están definitivamente vencidos, empiezan a ocupar la Patagonia: vienen del norte, de Neuquén, de Chile, de la Pampa Central, corridos por el máuser, por el arado y por las exigencias de una vida que significa trabajo, orden, paz, justicia, honradez e higiene a la que no pueden amoldarse. [...] Más tarde (en la actualidad) el hombre blanco ocupa la tierra disponible, los arrendamientos de los campos fiscales, y su consecuencia, los alambrados, obligan al indio a una vida sedentaria, e incapaz como es para ganársela en el trabajo, es acorralado por el hambre y la miseria. (Harrington 1936: 70)

Por otro lado, aun cuando reconocieron la vigencia del habla mapuche "a ambos lados del espinazo de los Andes" (Benigar 1924: 81), también recurrieron a la retórica de la extinción. En un mismo texto, Harrington afirmaba "todos mis alumnos aborígenes hablan araucano" y a la vez señalaba, de modo más genérico, que "el ejemplo del vecino, que no habla su lengua, los invade paulatinamente" (Harrington 1936: 73 y 70). Estos signos de desplazamiento en curso se observaban también en el área de la toponimia donde, según Groeber (1926: 8), las denominaciones indígenas se sustituían por otras en castellano. Tal situación sociolingüística ponía en tensión el ideal de documentar interpretaciones prístinas y seguras, y conllevaba dificultades para la elicitación en campo, que los autores leyeron como desinterés de sus interlocutores por brindar informaciones desde un rol de consultantes, similares a las manifestadas en la misma época por Lehmann-Nitsche en el sur de la provincia de Buenos Aires que hemos destacado más arriba: 
Son muy pocos los individuos que están dispuestos a dar informes. Entre ellos hay muchos que no pueden hacerlo, sea porque su conocimiento del araucano es muy reducido ya, o porque ni ellos, ni sus padres son oriundos de la región. (Groeber 1926: 4)

Para entender su razón, hay que tener presente que trato con individuos ya acostumbrados a ser interrogados y que conocen mi deseo de oír todo lo que saben respecto del objeto de la pregunta. De lo contrario, el indio se encerraría en su mutismo, del que penosamente se sacan lacónicas contestaciones, casi siempre evasivas. (Benigar 1927: 154-155)

Conscientes de que "del idioma de los araucanos existen vocabularios, gramáticas, narraciones y diccionarios más o menos completos" (Harrington 1925: 205), en sus textos reconocieron los aportes de la araucanística clásica, y también destacaron otras figuras más contemporáneas, en especial Lenz, Augusta, Lehmann-Nitsche y Milanesio. Así, por ejemplo, Groeber controló sus datos con las tres gramáticas jesuitas y el texto de Barbará, entre otros, pero adoptó "el alfabeto de los autores modernos y lingüistas de fama, como R. Lenz y Augusta" (Groeber 1926: 9). A la vez, criticó acremente a Milanesio (1915) por su toponimia que contenía repeticiones, traducciones erróneas, interpretaciones dudosas o falsas, y resaltó el trabajo en el tema de su contemporáneo San Martín, cuyas pocas interpretaciones erróneas se debían a la ausencia de datos obtenidos en el trabajo de campo. También Benigar reafirmó el valor de los referentes bibliográficos previos, pero abogó por no prestarles "una fe incondicional". En este sentido, señalaba:

Ni son las obras existentes tan completas, ni tan perfectas, ni tan claras, para que permitieran inferir deducciones seguras. Son todas ellas -cual más, cual menos- obras valiosísimas como documentos, tesoros que representan un esfuerzo enorme, un trabajo largo y paciente; pero para su buena interpretación y aprovechamiento exígense conocimientos más amplios, recogidos entre los indios.

No se engañe nadie, en presencia de vocabularios y gramáticas muy respetables, con la creencia de que ya todo está hecho. Mucho se ha hecho, mucho se ha salvado, pero falta lo más, y lo más importante, que nos dé la llave de la construcción de esa lengua, tan sencilla como difícil para nosotros, que hablamos lenguas de arquitecturas fundamentalmente distintas. Ahí está el trabajo que nos espera, y otro parecido aguardan quizá todas las lenguas sudamericanas... (Benigar 1924: 85-86) 
Se observa en sus autopresentaciones que estos intelectuales no se arrogaban prerrogativas de académicos ${ }^{12}$, si bien por el valor que se les otorgó a sus producciones, no fueron ni ajenos ni ignorados por los círculos científicos argentino y chileno. San Martín y Benigar fueron miembros correspondientes por Neuquén y Río Negro de la Junta de Estudios de Historia y Numismática Americana. Por otro lado, existe constancia de un intercambio temprano de correspondencia en la década del 20 entre Benigar y Lenz, y de este último con San Martín y con Groeber, así como entre Harrington y LehmannNitsche. Presentamos a continuación algunos testimonios de estas misivas a fin de destacar tópicos y representaciones en ellas consignados. En el caso de Harrington, la carta fue enviada al iniciarse en los trabajos sobre el tema -se instaló en Chubut como maestro ambulante en 1914 y comenzó sus estudios sobre las lenguas a fines de esa década al regresar a Buenos Aires (Vezub 2007). Efectúa la consulta al antropólogo alemán sobre algunos antropónimos en mapuzungun y le solicita bibliografía actualizada:

Para hacer comparaciones con mis apuntes, mejorarlos y explicarme algunas cosas hasta ahora para mi incomprensibles, quisiera adquirir algunos libros que se hayan publicado en este país o en Chile sobre el mismo tema, y como no tengo quien me asesore y se me informa que Ud. es la autoridad en tales asuntos, perdóneme si lo molesto con estas líneas. Lo que desearía saber es: que libros o folletos se han publicado que traten de la raza araucana, especialmente diccionarios y vocabularios de su idioma. Solo conozco el vocabulario de Barbará, bastante incompleto, por cierto, y que contiene, según mi escaso saber, términos mal interpretados o por lo menos mal vertidos al castellano.

12 Por ejemplo: "Por mero pasatiempo y sin ninguna pretensión, estoy interesado en formar un pequeño vocabulario de la lengua araucana" (Harrington, 1922); "[mi obra es] fruto del estudio en los días que sus temporales de nieve me retienen bajo techo, las cálidas emociones vividas en la soledad de sus montañas. [...] escribo en los momentos hurtados a las faenas rurales $[. .$.$] . No escribo por mero placer ni por la notoriedad que con ello pudiera alcanzar.$ Quiero llevar hasta mis lectores noticias y verdades interesantísimas, no vulgarizadas aun, acerca de estas regiones incorporadas sin fe de bautismo a la vida nacional" (San Martín, 1919: 15, 19); “... mi prolongado silencio. No se debe a la inactividad, sino al hecho que estoy preparando trabajos ya definitivos en cuanto a mí atañe. Dedícoles todo el tiempo libre que me deja mi lucha por el bienestar de mi familia. [...] Antes que pase un año oirán de mí, si encuentro cómo publicar mis escritos". (Carta de Juan Benigar a Ricardo Levene, Kelleñ Ko, 26 de octubre de 1936) 
Algo que no han podido explicarme los aborígenes - mi única fuente de información- es el significado de ciertas terminaciones de nombres que hoy son apellidos. Así por ejemplo, pan en Nahuelpán (Nahuel, tigre; pan ...??); Curapán, que yo escribo Cur-ra-pán, puesto que el aborigen dice a las claras cur-rá cuando quiere significar piedra; Millapán; Neipán o Naipan; Loncopan (Loncó, cabeza; pan...??).

Otra terminación frecuente es mil. V.g.: Catrimil (mejor Ca-trri-mil); Loncomil; Currumil (mejor Cur-rug-mil), que traducidos dicen: Catrrí, partido por el medio; Loncó, cabeza; Cur-rug, negro... quedando en ayunas en cuanto a la terminación mil. (Carta de Tomás Harrington a Roberto Lehmann-Nitsche, Colonia 16 de Octubre, 21 de diciembre de 1922)

Por su parte, las cartas originales de la correspondencia entre Benigar y Lenz aún no han podido ser halladas, y los comentarios que presentamos a continuación proceden del intercambio epistolar del filólogo alemán con Manuel Reguera, periodista español radicado en Buenos Aires. En este caso la correspondencia permite observar el lugar nodal que Lenz mantenía en la Argentina como referente en la temática para estos autores, y a la vez, su interés por estar actualizado sobre los saberes que se generaban al este de los Andes. Luego de que Reguera le acercara el recién aparecido artículo "El concepto del tiempo entre los araucanos", Lenz evaluaba a Benigar como "una persona con buena preparación científica general que está practicando la lengua mapuche precisamente en el dialecto menos conocido de la falda oriental de los Andes", señalaba que "él no debe quedar en su aislamiento sino ponerse en contacto con los pocos compañeros de trabajo que existen todavía", y alentaba a que publicara "cuanto antes materiales originales en lengua pampa con traducción literal y literaria y estudios analíticos de la gramática" (Carta de Rodolfo Lenz a Manuel Reguera, Santiago de Chile, 18 de octubre de 1924). En la primavera siguiente informaba:

De Benigar he recibido otra carta, hace poco. Estamos discutiendo cuestiones de gramática, para preparar el terreno. Ojalá tuviera bastante tiempo el pobre para dejar en limpio sus apuntes de documentos originales en lengua pampa. Espero mucho de él. (Carta de Rodolfo Lenz a Manuel Reguera, Santiago de Chile, 16 de septiembre de 1925)

En las misivas siguientes se pone de manifiesto que esa concepción elogiosa se mantuvo, ("[Benigar] sabe muchísimas cosas de mapuches mejor que nadie" (Carta de Rodolfo Lenz a Manuel Reguera, Santiago de Chile, 18 de septiembre de 1928), y aunque la comunicación entre ambos, según parece, se discontinuó hacia fines de 1925, Lenz continuó estando al tanto de sus producciones, así como de los debates 
en los que el croata se involucraba, primero con Lehmann-Nitsche ${ }^{13}$, y posteriormente con Imbelloni ${ }^{14}$. Por otro lado, Lenz también elogió la Toponimia de Groeber, expresando que "es lo mejor que he visto en esta clase de obras". (Carta de Rodolfo Lenz a Manuel Reguera, Santiago de Chile, 22 de septiembre de 1926)

En el plano del análisis lingüístico, San Martín, Groeber y Harrington expusieron en sus obras algunos observaciones específicas acerca de la morfología y la semántica del mapuzungun, de las que carecieron otros trabajos anteriores, por ejemplo, al analizar los topónimos. Benigar, por su parte, realizó avances descriptivos sustanciales, al encuadrarse en formatos explicativos de la disciplina e intentar profundizar en la fonología del "araucano oriental" (Benigar s/f en Álvarez 1981). Así, por ejemplo, estudió los sentidos léxico-gramaticales presentes en las expresiones de tiempo, espacio y causalidad en la lengua (Benigar 1924, 1925, 1927), así como el sustantivo y la voz pasiva (Bruno y Serafini 1994). Su proyecto de publicación, en una vasta producción descripta en de Miguel (2017), se plasmaría en una obra totalizadora denominada El indio araucano (de Miguel, c.p.).

Cabe señalar también que la lengua era para Benigar, en perspectiva humboldtiana, "la ventana por donde se asoma el alma de cada pueblo. $\mathrm{Su}$ conocimiento es indispensable para quien desea interpretar fielmente esa habla" (1927: 148). Por ello la investigación sobre la misma no podía limitarse ni al trabajo documental de gabinete, ni a ampliar el conocimiento lexicográfico accesible mediante listas de palabras y toponimias, ni al registro de textos, sino que exigía dedicar tiempo a su aprendizaje y asumir una perspectiva etnolingüística que permitiera vincular las expresiones frecuentes en el idioma con los perfilamientos y la relevancia que su ocurrencia denotaba en el nivel conceptual.

Largas han sido mis búsquedas para encontrar el equivalente araucano de la palabra castellana tiempo. Hacíame traducir todas las combinaciones imaginables en cuya construcción la usamos. Todo fue en vano, porque

13 "Del amigo Benigar no he oído nada directamente este año; pero veo por los recortes que Ud. mandó que está peleando con Lehmann-Nitsche (antiguo amigo mío!), que ha hecho algunas cosas útiles, pero no es propiamente filólogo" (Carta de Rodolfo Lenz a Manuel Reguera, Santiago de Chile, 4 de diciembre de 1926). Sobre este particular, véase también el cuestionamiento a un ejemplo en mapuzungun que considera que el investigador alemán no había sabido interpretar. (Benigar 1927: 145)

14 Benigar dedicó un libro completo, el volumen El problema del hombre americano (1928), a la crítica de La esfinge indiana aparecido dos años antes. 
el indio siempre encuentra una expresión adecuada, rodeando el concepto cristalizado del tiempo. El expresa el tiempo sin nombrarlo y para ello dispone de un surtido enorme de giros... [...] Su riqueza de adverbios temporales es admirable. Posee partículas que indican los tiempos gramaticales [...] ¡Sustantivos con indicación de tiempo! ¡Realmente! Así, entre muchas otras formas con que el araucano reemplaza el sustantivo nuestro "vivienda", encontraremos los de "müleam" que designa la vivienda futura; "müle peyem" la vivienda actual, y "müle pervüm (em)”, la vivienda anterior. (Benigar 1924: 83, 87)

En este sentido, ofreció en sus obras una mediación expresada en numerosos ejemplos en la lengua, segmentados morfológicamente y traducidos al español en versiones libres "plegadas al original solo hasta donde es hacerlo sin estropear la lengua" y evitó en cambio como modo de presentación la traducción interlineal utilizada por los colegas de la época, por "necesariamente defectuosa y antiestética", y poco útil además para los destinatarios de su obra, que no eran hablantes (1927: 152-153). Por último, en consonancia con su postura relativista esbozó en distintos comentarios una teoría de la traducción, en la que enfatizaba: "Quiero dejar constancia que no siempre es bueno querer traducirlo todo. Hay cosas intraducibles. Las hay para el araucano en el castellano, y las hay para nosotros en el araucano". (1925: 139)

Estos autores, y en particular Benigar, se convirtieron posteriormente en referentes para los estudios sobre el mapuzungun, activados desde los espacios intelectuales territorianos y provinciales. Recién la academia universitaria retomaría el interés por profundizar aspectos de este idioma, desde planteos descriptivos y de estudios del arte verbal, hacia fines de la década del 50, en vísperas del Primer Congreso del Área Araucana realizado en San Martín de los Andes. (Malvestitti y de Miguel 2020)

\section{CONCLUSIONES}

En el artículo analizamos los distintos abordajes que se realizaron sobre el mapuzungun en la Argentina entre 1885-1945, desde una perspectiva panorámica que intentó sistematizar las articulaciones y tensiones entre las investigaciones realizadas.

Pudimos observar además cómo los referentes gramaticales y lexicográficos jesuitas se mantuvieron vigentes, a la vez que a medida que 
avanzaba el siglo XX ganaban espacio Falkner, Lehmann-Nitsche y, más lateralmente, Milanesio, en la araucanística al este de los Andes. Visualizamos además la existencia de citación y relaciones entre investigadores argentinos y chilenos con la figura de Lenz como nodo de correspondencia. Desde un enfoque historiográfico lingüístico, registramos cómo la pregunta erudita acerca del pasado histórico del territorio pampeano se reconvirtió en la inquietud surgida desde el territorio (geográfico y social), que se proponía develar aspectos sociológicos y sistemáticos de la lengua, en particular su fonología, su morfología y ciertas áreas del léxico como los topónimos. Por otro lado, reconocimos que aun cuando no se anularon ciertos sesgos ideológicos en una argumentación que mantuvo referencias permanente en las fuentes históricas -también Benigar se refirió a las "migraciones" de occidente a oriente, y Harrington señaló que sus consultantes "afirman, sin excepción, que el 'dueño de la tierra' era el tehuelche" (1936: 71) ${ }^{15}$-, la mirada territoriana se construyó más empática con la realidad contemporánea de los pobladores, interlocutores necesarios y pares comunicativos para la producción de datos.

Cada uno de los autores abordados exige por sí un trabajo monográfico, a fin de exponer en detalle sus aportes específicos al tema analizado. No obstante, la consideración de la actividad secuencial de las distintas agencias, de sus ámbitos territoriales de desempeño y de los focos temáticos e ideologías que pusieron de manifiesto sobre la lengua y sobre el pueblo mapuche durante este lapso de sesenta años ha permitido comenzar a esclarecer cómo la ausencia de un programa de trabajo sistemático a nivel institucional, la casi general ausencia de profesionales de la lingüística en el tema, la dispersión de focos de estudio y, sobre todo, la carencia de difusión de muchos de los registros y resultados de investigación, obstruyeron en el periodo considerado ampliar en avances significativos el conocimiento del mapuzungun al este de los Andes.

\section{REFERENCIAS BIBLIOGRÁFICAS}

Adelung, Johann Christoph y Johann Severin Vater. 1806-1817. Mithridates oder allgemeine Sprachenkunde mit dem Vater Unser als Sprachprobe in beynahe fünfhundert Sprachen und Mundarten. 6 volúmenes. Berlín: Vossische Buchhandlung.

15 Sobre este tema, véase también el análisis de Pérez (2009). 
Augusta, Félix José. 1903. Gramática Araucana. Valdivia: Imprenta Central Lambert.

BarbarÁ, Federico. 1879. Manual o Vocabulario de la Lengua Pampa y del Estilo Familiar. Buenos Aires: Imprenta y Librería de Mayo de C. Casavalle.

Barros Arana, Diego y Rodolfo Lenz. 1893. La lingüística americana, su historia i su estado actual. Santiago de Chile: Imprenta Cervantes.

Benigar, Juan. 1924. El concepto del tiempo entre los araucanos. Boletín de la Junta de Historia y Numismática Americana 1: 137-154.

1925. El concepto de espacio entre los araucanos. Boletín de la Junta de Historia y Numismática Americana 2: 67-83.

1926. El calvario de una tribu. Biblos (Azul) 3, (11): 30-48.

1927. El concepto de la causalidad entre los araucanos. Boletín de la Junta de Historia y Numismática Americana 4: 245-263.

1928. El problema del hombre americano. Bahía Blanca: Panzini Hermanos.

1936. Carta de Juan Benigar a Ricardo Levene, Kelleñ Ko, 26 de octubre de 1936.

Biblioteca Nacional de Maestros, Buenos Aires. Recuperado de http://www.bnm.me.gov. ar/catalogo/Record/000121760/Holdings [Consulta 14/12/2019].

1978. La Patagonia piensa. Neuquén: Siringa.

1981. El indio araucano. Gramática araucana. En Gregorio Álvarez. Neuquén, tomo V, pp. 203-273. Neuquén: Gobierno de la Provincia del Neuquén.

Brinton, Daniel. 1891. The American Race. A linguistic classification and ethnographic description of the native tribes of North and South America. New York: N. D. C. Hodges.

Bruno, Lidia y Mirta Serafini. 1994. Benigar, un sabio desconocido de la Patagonia. Lengua y Literatura Mapuche 6: 57-64.

Canio Llanquinao, Margarita y Gabriel Pozo Menares. 2013. Historia y conocimiento oral mapuche. Sobrevivientes de la "Campaña del desierto" y "Ocupación de la Araucanía" (1899-1926). Santiago de Chile: Lom Ediciones.

Cañas Pinochet, Alejandro. 1911. Estudios de la lengua veliche. En Carlos Porter (ed.). Trabajos del Cuarto Congreso Científico ( $1^{\circ}$ Pan-Americano). Trabajos de la III Sección - Ciencias Naturales, Antropológicas y Etnológicas, pp. 143-330. Santiago de Chile: Imprenta Barcelona.

Chamberlain, Alexander. 1913. Linguistic Stocks of South American Indians, with Distribution-Map. American Anthropologist 15 (2): 236-247.

DARAPSKY, Luis. 1888. La lengua araucana. Santiago: Imprenta Cervantes.

Da Rosa, Juan. 2013. "Historiografía lingüística del Río de la Plata: las lenguas indígenas de la Banda Oriental”. Boletín de Filología XLVIII (2): 131-171.

De Mauro, Sofía. 2018. El Catálogo razonado de Bartolomé Mitre y la lingüística indígena americana a fines del siglo XIX en Argentina. RASAL. Revista de la Sociedad Argentina de Estudios Lingüisticos, pp. 67-86.

De Miguel, Rodrigo. 2017. Los manuscritos inéditos de Juan Benigar: la catalogación realizada por Bruno y Serafini (1995). VIII Jornadas Internacionales de Filología y Lingüística, 21 al 23 de junio de 2017, La Plata, Argentina. [en línea] Disponible en: http://www.memoria.fahce.unlp.edu.ar/trab_eventos/ev.10694/ev.10694.pdf [Consulta 07/07/2019].

DomíngueZ, Luisa. 2018. Lenguas indígenas a comienzos del siglo XX en Argentina. Ponencia presentada en el XVI Congreso de la Sociedad Argentina de Estudios Lingüísticos, Universidad Nacional de San Martín, Campus Miguelete, Buenos Aires, 3 al 6 de julio de 2018.

Domínguez, Luisa y Rodrigo de Miguel. 2018. Un debate antropológico-lingüístico sobre los orígenes del hombre americano a comienzos del siglo XX en Argentina. En Alejandra 
Regúnaga, Silvia Spinelli y María Emilia Orden (eds.). Actas del IV Encuentro de Lenguas Indigenas Americanas, pp. 233-248. Santa Rosa: EdUNLPam.

ENNIS, JuAN. 2018. Las novedosas ciencias del lenguaje y las políticas de sus usos: Vicente Fidel López en la Revista de Buenos Aires (1863-1869). Boletín de la Sociedad Española de Historiografía Lingüística 12: 53-74.

FARro, MÁximo. 2013. Las lenguas indígenas argentinas como objeto de colección. Notas acerca de los estudios lingüísticos de Samuel A. Lafone Quevedo a fines del siglo XIX. Revista de Indias LXXIII, 258: 525-552.

y Sofía de Mauro. 2019. Máquinas de papel y lenguas indígenas americanas. Los archivos de trabajo de Samuel Lafone Quevedo y Bartolomé Mitre. CHUY Revista de Estudios Literarios Latinoamericanos 6. [en línea]. Disponible en http://www. revistasuntref.com.ar/index.php/chuy/article/view/316 [Consulta 03/12/2019].

Febrés, Andrés. 1765. Arte de la lengua general del Reyno de Chile. Lima: Calle de la Encarnación.

Groeber, Pablo. 1926. Toponimia Araucana. Buenos Aires: Sociedad Argentina de Estudios Geográficos.

GutiérRez, JuAn María. 1871. Algunas observaciones sobre la lengua Araucana y Guarani. Revista del Río de la Plata 6: 198-230.

Harrington, Tomás. 1922. Carta a Roberto Lehmann-Nitsche, Colonia 16 de Octubre, 21 de diciembre de 1922. Instituto Ibero-Americano de Berlín, N-0070 b 286.

1925. Algo sobre la lengua puelche o künnü. Anales de la Sociedad Científica Argentina 99: 205-206.

1935. Observaciones sobre vocablos indios. Publicaciones del Museo Antropológico y Etnográfico de la Facultad de Filosofía y Letras III: 59-69.

1936. Una escuela en el Chubut. El Monitor de la Educación Común 765: 69-74.

1942. Voces araucanas usuales en nuestro idioma. El Monitor de la Educación Común 831: 22-30.

Havestadt, Bernardo. 1883 [1777]. Chilidúgu sive tractatus Linguae Chilensis. Leipzig: B. G. Teubner.

Hervás y Lorenzo Panduro. 1800. Catálogo de las lenguas de las naciones conocidas, y numeración, división, y clases de estas según la diversidad de sus idiomas y dialectos. Madrid: Imprenta de la Administración del Real Arbitrio de Beneficencia.

ImBELLONI, JosÉ. 1936b. Lenguas indígenas del territorio argentino. En Levene, Ricardo (dir.). Historia de la Nación Argentina, tomo I, pp. 177-205. Buenos Aires: El Ateneo.

IRvine, Judy y Susan Gal. 2000. Language ideology and linguistic differentiation. En Paul Kroskrity (ed.). Regimes of language: Ideologies, polities and identities, pp. 35-83. Santa Fe: School of American Research Press.

KoERNER, E. F. K. 1999. On the place of linguistic historiography within the language sciences, again. En Sylvain Auroux (ed.). History of Linguistics 1999, pp. 373-388. AmsterdamPhiladephia: John Benjamins.

Kroskrity, Paul. 2004. Language Ideologies. En Alessandro Duranti (ed.). A Companion to Linguistic Anthropology, pp. 496-517. Oxford: Blackwell.

La Grasserie, Raoul De. 1891. La langue auca (ou langue indigene du Chili): Grammaire, Dictionnaire, Textes Traduits et Analysés. París: J. Maisonneuve.

Lafone Quevedo, Samuel. 1892. Las lenguas argentinas y el Museo de La Plata. II. La Nación, 7 de octubre de 1892.

1898. Cuaderno Gennaken. Ms. Copiado por Bartolomé Mitre. Museo Mitre, Buenos Aires. 
1900. La raza pampeana y la raza guaraní ó Los indios del Río de La Plata en el siglo XVI. En Samuel A. Lafone Quevedo y Félix Outes (comps.). Actas de la Primera reunión del Congreso Cientifico Latino Americano celebrada en Buenos Aires del 10 al 20 de 1898 por iniciativa de la Sociedad Cientifica Argentina. V. Trabajos de las 4ta sección (Ciencias antropológicas y sociológicas), pp. 27-135. Buenos Aires: Compañía Sud-Americana de Billetes de Banco.

1909. Etnología Argentina. La Universidad Nacional de La Plata en el IV Congreso Científico, I Panamericano, pp. 176-215. Buenos Aires: Coni.

Larsen, Juan Mariano. 1884. Al lector. En Andrés Febrés. Gramática araucana; ó sea, Arte de la lengua general de los Indios de Chile, pp. iii-viii. Buenos Aires: Juan A. Alsina.

LAtham, Robert GoRdon. 1868. The languages of South America, with special reference to the value of some of them as media for missionary teaching. South American Missionary Magazine, 1 de septiembre, 3: 133-135.

LeHMANN-Nitsche, RoBerTo. 1901. Zur araukanischen Volkskunde. Instituto Ibero-Americano de Berlín, N-0070 w 23.

1906a. Europäische Märchen unter den argentinischen Araukanern. XIV Congreso Internacional de Americanistas 10 (2): 681-694.

1906b. Märchen der argentinischen Indianer. Zeitschrift des Vereins für Volkskunde in Berlin 2: 156-161.

1922. El grupo lingüístico 'het' de la pampa argentina. Revista del Museo de La Plata XXVII: $10-85$.

1925. Reise nach Curamalal. Instituto Ibero-Americano de Berlín, N-0070 13.

1930. Mitología Sudamericana XVI. El viejo Tatrapai de los Araucanos (Primera parte). Revista del Museo de La Plata XXXII: 41-56.

Lenz, Rodolfo. 1895-1897. Estudios Araucanos. Santiago de Chile: Imprenta Cervantes.

1924. Carta a Manuel Reguera, Santiago de Chile, 18 de octubre de 1924. Archivo UMCE, 3-1028.

1925. Carta a Manuel Reguera, Santiago de Chile, 16 de septiembre de 1925, Archivo UMCE, 3-1032.

1926a. Carta a Manuel Reguera, Santiago de Chile, 22 de septiembre de 1926. Archivo UMCE, 3-1037.

1926b. Carta a Manuel Reguera, Santiago de Chile, 4 de diciembre de 1926. Archivo UMCE, 3-1040.

1928. Carta a Manuel Reguera, Santiago de Chile, 18 de septiembre de 1928. Archivo UMCE, 3-1044.

LOUKOTKA, Č́STMIR. 1929. Vocabularios inéditos o poco conocidos de los idiomas rankelche, guahibo, piaroa, toba, pilagá, tumanahá, kaduveio, etc. Revista del Instituto de Etnología de la Universidad Nacional de Tucumán 1: 75-106.

Malvestitti, Marisa. 2012. Mongeleluchi zungu. Los textos araucanos documentados por Roberto Lehmann-Nitsche. Berlín: Ibero-Amerikanisches Institut / Gebr. Mann Verlag.

2018. Dimensiones teórico-metodológicas en dos vocabularios del mapuzungun registrados en Puelmapu. En Beatriz Neumann (ed.). Encuentro textual. Ensayos sobre literaturas y lenguas. Tomo 2, pp. 177-193. Trelew: EDUPA, ILLPAT, UNPSJB.

y Rodrigo DE Miguel. 2020. Controversias lingüísticas e ideologías sobre el mapuzungun en el Primer Congreso del Área Araucana Argentina. Forma y Función, 33 (1): 13-37.

y María Emilia Orden. 2019. La documentación de las lenguas patagónicas en el gabinete de Samuel Lafone Quevedo. El Vocabulario Guenaken. Journal de la Societé des Américanistes 105-2: 133-164. 
Martínez, Ana Teresa. 2013. Intelectuales de provincia: entre lo local y lo periférico. Prismas. Revista de Historia Intelectual 17 (2): 169-180.

Medina, José Toribio. 1897. Bibliografía de la Lengua araucana. Nueve sermones en Lengua de Chile por el P. Luis de Valdivia. Santiago de Chile: Imprenta Elseviriana, pp. 17-73.

Milanesio, Domenico. 1898. La Patagonia, lingua, industria, costumi e religione dei Patagoni. Buenos Aires: Escuela Profesional de Tipógrafos de Colegio Pio IX de Artes y Oficios.

1915. Etimología araucana. Idiomas comparados de la Patagonia. Lecturas y frasario araucano. Buenos Aires, Talleres Gráficos del Estado Mayor del Ejército.

Mitre, Bartolomé. 1909. Catálogo razonado de la Sección Lenguas americanas. Tomos I, II y III. Buenos Aires: Imprenta de Coni Hermanos.

Niederehe, Hans-Josef. 1995. Bibliografía cronológica de la lingüística, la gramática y la lexicografía del español (BICRES): desde los comienzos hasta el año 1600. AmsterdamPhiladephia: John Benjamins.

Nicoletti, María Andrea y Marisa Malvestitti. 2008. El uso de la lengua aborigen como práctica de evangelización: Domingo Milanesio y su prédica en mapuzungun (fines del siglo XIX y principios del siglo XX). Fronteras de la Historia 13 (1): 95-118.

Ortelli, Sara. 1996. La "araucanización” de las pampas: ¿realidad histórica o construcción de los etnólogos? Anuario del IEHS 11: 203-225.

OutEs, FÉLIX. 1914. Un texto y un vocabulario en dialecto pehuenche de fines del siglo XVIII con introducción y notas. Revista del Museo de La Plata XXV: 68-73.

y CARLos Bruch. 1910. Los aborígenes de la República Argentina. Buenos Aires: Ángel Estrada y Cía.

Pegoraro, Andrea. 2009. Las colecciones del Museo Etnográfico de la Universidad de Buenos Aires: un episodio en la historia del americanismo en la Argentina 1890-1927. Tesis para optar al grado de Doctora en Antropología, Universidad de Buenos Aires.

Pérez, Liliana. 2009. Y recuerde que lo dijo Trüülmaní. Tomas Harrington y los Gününa Küna, Chubut 1911-1935. Otros Logos. Revista de Estudios Críticos 8: 130-147.

Portnoy, Antonio. 1936. Estado actual del estudio de las lenguas indígenas que se hablaron en el territorio hoy argentino. Buenos Aires: Instituto Mitre.

Rivet, Paul. 1924. Langues américaines. En Antoine Meillet y Marcel Cohen (dirs.). Les Langues du monde: par un groupe de linguistes. París: E. Champion, pp. 597-712.

Rosas. Juan Manuel De. 1947. Gramática y Diccionario de la Lengua Pampa (PampaRanquel-Araucano). Buenos Aires: Albatros.

San Martín, Félix. 1919. Neuquén. Toponimia araucana del Neuquén. Buenos Aires: s.d.

Savino, Pablo Emilio. 1876. Pequeño Manual del Misionero para evangelizar a los indios fronterizos. Buenos Aires: Imprenta de Pablo Coni.

SWiggers, PierRe. 2012. Linguistic historiography: object, methodology, modelization. Todas as Letras $S, 14$ (1): 38-53.

Ten Kate, Hermann. 1906. Matériaux pour servir á l'anthropologie des Indiens de la République Argentine. Revista del Museo de La Plata XII: 31-64.

VALDIVIA, LuIS DE. 1606. Arte y Gramatica general de la lengua que corre en todo el Reyno de Chile, con un Vocabulario y Confessonario. Lima, Francisco del Canto.

VezuB, Julio. 2007. Historiar las prácticas etnográficas. Tomás Harrington y la morfología de la cultura en Patagonia septentrional hacia 1940. En Antonio Escobar, Raúl Mandrini y Sara Ortelli (eds.). Sociedades en movimiento. Los pueblos indígenas de América Latina en el siglo XIX, pp. 175-188. Tandil: IEHS/UNCPBA. 